\title{
PROGNÓSTICO DO LAZER NAS DIFERENTES AGENDAS SETORIAIS 12
}

Recebido em: 20/11/2019

Aprovado em: 05/05/2020

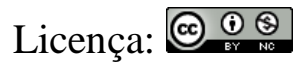

Ricardo Alves Mendes3

Giuliano Gomes de Assis Pimentel4

Universidade Estadual de Maringá (UEM)

Maringá - PR - Brasil

RESUMO: Com a globalização, a atividade prospectiva se tornou cada vez mais complexa. Nesse sentido, buscamos compreender os sentidos dados ao lazer nas agendas globais setoriais (saúde, meio ambiente, economia). Para tanto, realizamos análise documental de 6 agendas subscritas por agências internacionais, nacionais ou locais. A exegese crítica do material apontou que o lazer é analisado de forma parcial, predominantemente como um campo afetado pelo desenvolvimento tecnológico e econômico ou como meio para promoção da saúde no contexto do desenvolvimento social e ambiental.

PALAVRAS-CHAVE: Atividades de Lazer. Política Pública. Trabalho.

\section{PROGNOSIS OF LEISURE IN THE DIFFERENT SECTORAL AGENDAS}

ABSTRACT: With globalization, prospective activity has became increasingly complex. In this sense, we seek to understand the meanings given to leisure in global sectoral agendas (health, environment, economy). Therefore, we conducted document analysis of 6 agendas subscribed by international, national or local agencies. The critical exegesis of the material indicated that leisure is partially analyzed, predominantly as a field affected by technological and economic development or as a means for health promotion in the context of social and environmental development.

KEYWORDS: Leisure Activities. Public Policy. Work.

\section{Introdução}

O lazer, além de ser considerado um direito e uma dimensão da cultura, é um dispositivo social de controle do tempo livre (PIMENTEL, 2018). Portanto, se vê

\footnotetext{
1 Este trabalho teve o apoio da Rede CEDES.

2 Artigo premiado no 30. Encontro Nacional de Recreação e Lazer (ENAREL), realizado em Curitiba/PR em 2019.

3 Doutorando em Educação Física pela Universidade Estadual de Maringá (UEM).

4 Professor Associado da Universidade Estadual de Maringá (UEM) e do Programa Associado UEM/UEL de Pós-Graduação em Educação Física. Coordena o Grupo de Estudos do Lazer (GEL).
} 
sujeito a disputas de consenso local e global, particularmente no que tange ao seu futuro, numa sociedade marcada por transformações transnacionais. A nosso ver, a capilaridade do lazer o coloca tanto na mira das tendências mundiais quanto nas táticas de resistências locais. Para pensar a gestão e as políticas de lazer, portanto, para posterior esforço de síntese, nos cabe conhecer essas polaridades. Frente a isso, realizamos um juízo crítico de como o lazer é compreendido nas agendas setoriais da economia, da tecnologia, da saúde e do meio ambiente.

As agendas são resultado dos mecanismos de planejamento, com vistas a criar e planejar ações e estratégias programadas para atingir determinado objetivo. Seus agenciadores são instituições estatais e paraestatais, as quais buscam planejar as cidades, os países e, consequentemente, o mundo para os próximos 12 a 20 anos. Com isso, surge a Agenda que é um plano de ação para as pessoas, redigida por grupo de atores estratégicos, de diferentes setores, cujo propósito comum é voltado à solução de um problema social específico (SENAI/PR, 2017; MMA, 1992).

Um dos aspectos marcantes da globalização, fenômeno predominantemente econômico, é a formulação de agendas globais. Elas produzem prognósticos setoriais (ciência, comércio, trabalho, turismo, entre outros) em média para os próximos 17 anos. Precisamos considerar a crítica ao epistemicídio embutido nesses documentos, os quais tendem a ser uma imposição dos países centrais aos periféricos (GERMANO; SILVA, COSTA, 2013). Por outro lado, é no concreto da vida cotidiana local que os agentes resistem ou reforçam os prognósticos (SOGREN e NATHANIEL, 2017). Assim, é fundamental conhecer o conteúdo dessas agendas (locais e globais) a fim de que avaliemos o impacto delas na sistematização da própria agenda do lazer.

Frente essas considerações, o objetivo deste estudo foi verificar como o lazer é compreendido nas agendas setoriais da economia, da tecnologia, da saúde e do meio 
ambiente. Com isso, buscamos conhecer o conteúdo das agendas (locais e globais) com o propósito de avaliar o impacto delas na sistematização da própria agenda do lazer.

\section{Metodologia}

Foram analisados os documentos que necessariamente não são de setores ligados ao lazer. Assim, foram escolhidas agendas como a do Turismo ou documentos da World Leisure Organization, até porque as projeções dessa entidade são de curto prazo. Outro critério para inclusão foi trabalhar com a projeção de tendências, constituindo uma agenda para o setor. Por fim, o documento precisaria conter menção ao lazer em uma perspectiva intersetorial, ou seja, perspectivar o lazer como uma das esferas de influência dessa agenda, seja ela considerada global, nacional ou local. Frente a isso, fizeram parte da presente pesquisa documental:

Quadro 1: Caracterização do material documental analisado.

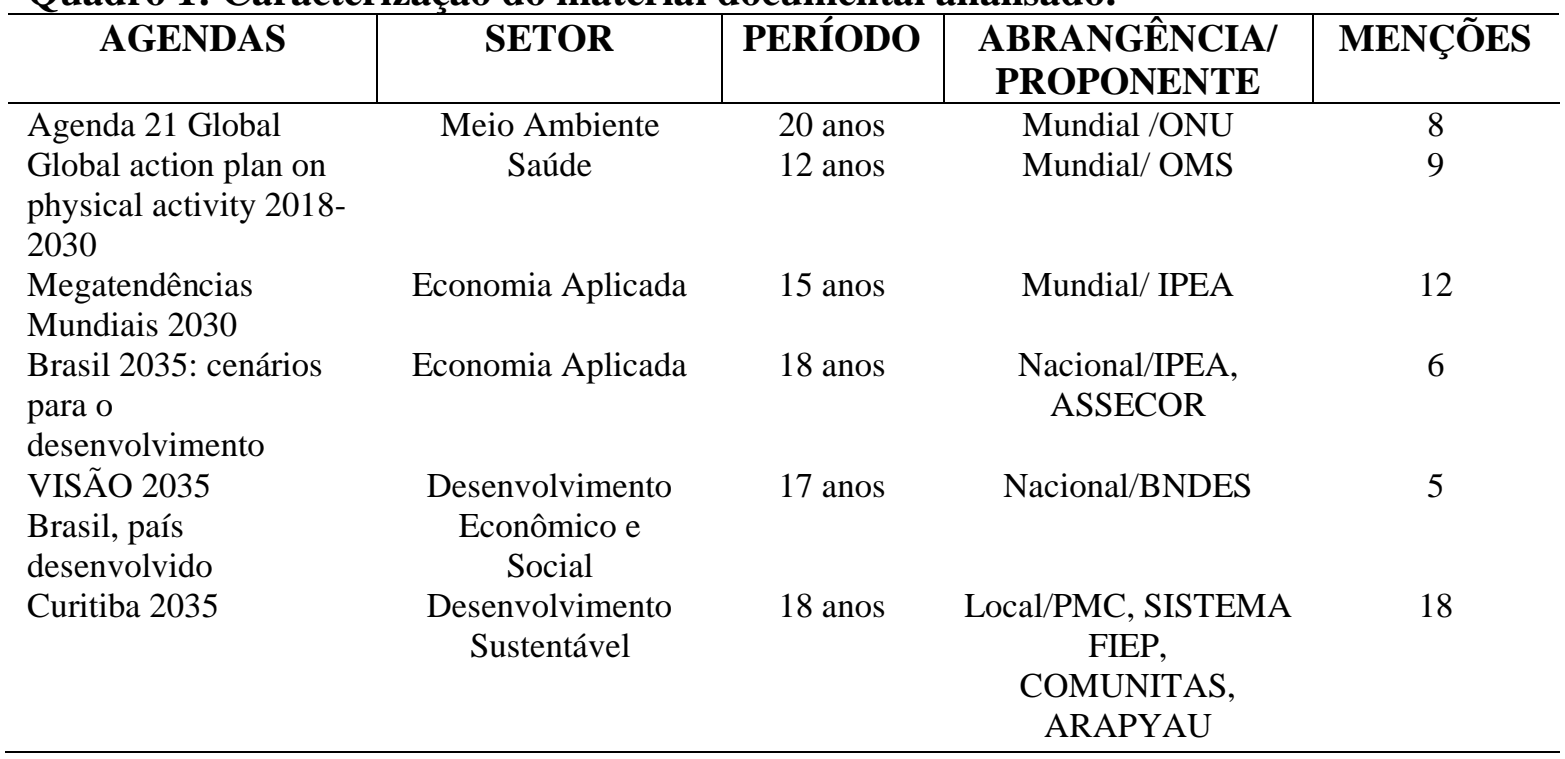

Após a seleção do material, foram utilizados termos de busca a fím de especificar em quais capítulos e temáticas essas agendas setoriais trazem diagnósticoprognósticos relativos ao lazer: lazer, tempo livre, recreação, cultura e entretenimento. O Quadro acima especifica em quantas ocasiões (menções) cada agenda aportou 
relações com o lazer. Também é possível caracterizar o setor (meio ambiente, saúde, economia, desenvolvimento econômico/social e desenvolvimento sustentável) a que se referem, as entidades envolvidas em sua formulação (proponentes), a abrangência prospectiva (em anos) e territorialidade (mundial, nacional e/ou local) respectivamente, conforme quadro 1.

\section{Apresentação Sintética do Referencial Teórico Utilizado para a Análise dos Dados}

O lazer foi aqui entendido como o dispositivo social que controla os usos culturais no tempo livre (PIMENTEL, 2018). A análise considerou a exegese hermenêutica dos documentos em função de duas categorias: (1) dimensões intrínsecas ao lazer e (2) propósitos dados ao lazer pelas agendas setoriais. Sobre o lazer nossa análise levou em consideração as ênfases dadas por cada documento em quatro subcategorias (tempo, espaço-lugar, manifestações culturais e ações ou atitude). Elas estão identificadas, entre outros, por Gomes (2004):

Tempo: corresponde ao uso do período presente em que não há obrigação de realizar uma determinada tarefa, ou seja, uma parcela significativa do tempo em que as pessoas não têm obrigações e não seguem os tempos institucionalizados para o lazer, como férias, intervalo escolar (recreio) e finais de semana.

Espaço-lugar: a dimensão espacial, seja física e/ou simbólica, onde se vivencia o lazer. Manifestações culturais: tópicos vivenciados a partir do aproveitamento da cultura com o propósito de diversão, de descanso e/ou desenvolvimento pessoal.

Ações ou atitude: fundamentadas em atividades lúdicas, expressões do ser humano de acepção da/na cultura relacionada com o brincar com o outro, consigo e com a realidade. 
Para a discussão da temática setorial, também a posteriori, capturamos subcategorias que denotam propósitos dados por essas agendas ao lazer, de forma intencional ou não. Os propósitos identificados foram: saúde, qualidade de vida, desenvolvimento econômico, direito social, tecnologia, educação, desenvolvimento sustentável, infraestrutura urbana e gestão urbana.

\section{Apresentação dos Principais Resultados}

Considerando a totalidade das agendas deste estudo, as três primeiras são planejadas com ações e estratégias para atingir objetivos voltados ao meio ambiente, saúde e economia aplicada, respectivamente, com abrangência mundial e são elas: (1) Agenda 21 Global (ONU), (2) Global action plan on physical activity 2018-2030 (OMS), (3) Megatendências Mundiais 2030 (IPEA). Optamos por analisar o material em língua portuguesa e, quando só houvesse em inglês, como no caso da OMS, realizamos a versão para a língua pátria.

Especificamente, o documento "Megatendências" apesar de ser um documento em que entidades e personalidades internacionais pensam sobre o futuro do mundo, ele é uma contribuição para um debate de longo prazo para o Brasil.

As próximas duas agendas possuem abrangência nacional com objetivos de economia aplicada e desenvolvimento econômico/social, respectivamente, e são elas: (4) O Brasil 2035: cenários para o desenvolvimento (IPEA, 2017), (5) VISÃO 2035: Brasil, país desenvolvido (BNDES, 2018). E por último, temos o documento (6) CURITIBA 2035 (SENAI/PR, 2017) com abrangência local e com objetivo de desenvolvimento sustentável de Curitiba.

\section{1) Agenda 21 Global - ONU, 1992}

licere, Belo Horizonte, v.23, n.2, jun/2020. 
Em 1992, a Organização das Nações Unidas (ONU) realizou, no Rio de Janeiro, a Conferência das Nações Unidas sobre o Meio Ambiente e o Desenvolvimento (CNUMAD) que ficou conhecida como ECO92 ou Rio 92, ou ainda, “Cúpula da Terra”. Esta conferência por ter mediado acordos entre os Chefes de Estado de 179 países participantes que acordaram e assinaram a Agenda 21 Global, também conhecida como Agenda 21 (BRASIL,1994).

Esse programa de ação resultou em um documento de 40 capítulos e constituiu a mais abrangente tentativa já realizada de promover, globalmente, o então denominado “desenvolvimento sustentável”. A Agenda 21 pode ser definida como um instrumento de planejamento para a construção de sociedades sustentáveis, em diferentes bases geográficas, que concilia métodos de proteção ambiental, justiça social e eficiência econômica (BRASIL,1994).

A Organização das Nações Unidas (ONU) é uma organização internacional formada por países que se reuniram voluntariamente para trabalhar pela paz e o desenvolvimento mundiais. $\mathrm{O}$ direito de tornar-se membro das Nações Unidas cabe a todas as nações amantes da paz que aceitarem os compromissos da Carta e que, a critério da ONU, estiverem aptas e dispostas a cumprir tais obrigações. A ONU possui hoje 193 Países-membros. Desde 1947 a ONU fixou representação no Brasil. A presença desta organização em cada país varia a depender das demandas apresentadas pelos respectivos governos (MMA, 2019).

A Agenda 21 teve o propósito de mudança para um novo modelo de desenvolvimento para o século XXI a partir da sistematização de um plano de ações com o objetivo de alcançar o desenvolvimento sustentável. (MMA, 2019) A inovação trazida por essa agenda foi colocar em primeira ordem o meio ambiente o que 
geralmente costumava ficar sempre em último lugar quando o assunto era desenvolvimento.

Os principais objetivos da Agenda 21 foram: verificar as mudanças ocorridas depois da Conferência de Estocolmo em 1972; aprimorar a legislação ambiental internacional; apontar técnicas regionais e globais para ações adequadas considerando as principais questões ambientais; sugerir estratégias de ações nacionais e internacionais para a proteção ambiental por meio de políticas de desenvolvimento sustentável; promover estratégias de desenvolvimento sustentável; examinar técnicas de eliminação da pobreza nos países em desenvolvimento (MMA, 2019).

Pode-se diagnosticar no preâmbulo do documento, que a humanidade se encontrava em um momento de definição histórica e isso fez com que houvesse um enfretamento das disparidades existentes entre as nações e no interior delas, o agravamento da pobreza, da fome, das doenças e do analfabetismo, e com a deterioração contínua dos ecossistemas de que depende nosso bem-estar (MMA, 2019).

Como prognóstico, a Agenda 21 está voltada para os problemas prementes do momento e tem o objetivo de preparar o mundo para os desafios do século XXI. Reflete um consenso mundial e um compromisso político no que diz respeito a desenvolvimento e cooperação ambiental. O êxito de sua execução é responsabilidade dos Governos.

Para concretizá-la, são cruciais as estratégias, os planos, as políticas e os processos nacionais. A cooperação internacional deverá apoiar e complementar tais esforços nacionais. Nesse contexto, o sistema das Nações Unidas tem um papel fundamental a desempenhar. Outras organizações internacionais, regionais e subregionais também são convidadas a contribuir para tal esforço. A mais ampla 
participação pública e o envolvimento ativo das organizações não-governamentais e de outros grupos também devem ser estimulados.

Entre as 8 citações a respeito do Lazer contidas na Agenda 21 Global, destacamos dois aspectos importantes, ou seja, 6 citações referentes a espaço-lugar e 2 citações que enfatizam o lazer como manifestação cultural.

No primeiro tipo de tratamento, o lazer surge como uma forma de espaço-lugar que se soma aos demais equipamentos necessários ao desenvolvimento das pessoas em assentamentos urbanos. Esse tipo de discussão aparece na introdução do capítulo 7 que trata da "Promoção do desenvolvimento sustentável dos assentamentos humanos" e no item B "Aperfeiçoar o manejo dos assentamentos humanos" do mesmo capítulo, exemplificada abaixo em uma das citações:

Em muitas regiões do mundo, em especial nos países em desenvolvimento, as condições dos assentamentos humanos vêm se deteriorando, sobretudo em decorrência do baixo volume de investimentos no setor, imputável às restrições relativas a recursos com que esses países se deparam em todas as áreas. Nos países de baixa renda sobre os quais há dados recentes, apenas 5,6 por cento do orçamento do Governo central, em média, foram dedicados a habitação, lazer, seguridade social e bem-estar social (1). Os recursos oriundos de organizações internacionais de apoio e financiamento são igualmente baixos (MMA, 2019).

No segundo momento, o lazer surge como manifestação cultural com o propósito de desenvolver outras oportunidades de emprego, tanto em atividades agrícolas como não-agrícolas. Esse tipo de discussão, por exemplo, aparece no capítulo 14 ao tratar da "promoção do desenvolvimento rural e agrícola sustentável":

\footnotetext{
Quando for impossível intensificar os sistemas de cultivo será preciso identificar e desenvolver outras oportunidades de emprego -- tanto em atividades agrícolas como não-agrícolas --, por exemplo indústrias de fundo de quintal, utilização da flora e da fauna silvestres, aquicultura e piscicultura, atividades não-agrícolas como pequena indústria com base nos povoados rurais, transformação de produtos agrícolas, agroindústria, lazer e turismo, etc (MMA, 2019).
}

licere, Belo Horizonte, v.23, n.2, jun/2020. 
Os últimos planos setoriais conduzem no seu discurso a interiorização do desenvolvimento turístico, com isso houve o aumento de estratégias para o desenvolvimento do turismo em locais que, até então, não possuíam qualquer orientação para propagar essa atividade. O turismo como lazer é uma realidade mundial. Lugares nunca antes visitados passam integrar roteiros turísticos das mais diversas modalidades (SILVA e MIRANDA, 2013).

\section{2) Global Action Plan on Physical Activity 2018-2030: More Active People}

\section{Healthier World - OMS, 2018}

O "Plano de ação global para a atividade física 2018-2030: mais pessoas ativas para um mundo mais saudável" da resposta às solicitações dos países sobre orientações mais atualizadas, e um quadro de ações políticas efetivas e viáveis para aumentar os níveis AF. Ele estabelece 4 grandes objetivos e propõe 20 ações políticas que são aplicáveis a todos os países abordando os múltiplos determinantes culturais, ambientais e individuais da inatividade (OMS, 2018).

Essa implementação exigirá uma forte liderança com parcerias intergovernamentais e multissetoriais, sem a qual o documento entende não haver uma resposta relevante do sistema. A OMS apoiará os países a ampliar e fortalecer a sua resposta com soluções políticas baseadas na evidência, diretrizes e ferramentas de implementação, e irá monitorizar o progresso e o impacto globais (OMS, 2018).

O documento tem o propósito de diminuir a inatividade física, criar sociedades ativas, ambientes ativos, pessoas ativas e sistemas ativos, bem como contribuir para alcançar os Objetivos para o Desenvolvimento Sustentável (ODS) de 2030 (OMS, 2018).

licere, Belo Horizonte, v.23, n.2, jun/2020. 
Segundo a OMS (2018), já é comprovado cientificamente que a prática regular de AF contribui na prevenção e no tratamento de várias doenças crônicas degenerativas não transmissíveis, como doenças cardíacas, acidente vascular, diabetes e outras, mas também auxilia na prevenção da hipertensão, do excesso de peso e da obesidade, além de contribuir para a saúde mental, melhoria da qualidade de vida e bem-estar das pessoas.

Mesmo assim, como diagnóstico, a população mundial está cada vez mais sedentária. À medida que os países se desenvolvem economicamente, os níveis de sedentarismo aumentam. Em alguns países, a inatividade física já atingiu $70 \%$ devido às mudanças nos meios de transporte utilizados, aumento do uso de tecnologias, valores culturais e urbanização (OMS, 2018).

O documento da OMS (2018) possui o prognóstico, de incentivar a população mundial de diminuir a inatividade física em $10 \%$ até 2025 e $15 \%$ até 2030, bem como, que esse incentivo seja realizado em parceria, investido em ações políticas para promover que as pessoas, em geral, andem a pé ou de bicicleta, façam esporte, e participem em atividades recreativas, em brincadeiras fisicamente ativas e, tudo isso, pode promover o bem-estar e a qualidade de vida para todos.

A Organização Mundial da Saúde (OMS) apoiará os países a implementar abordagens integrando todos os parceiros em cada comunidade ou território, visando o aumento da atividade física em pessoas de todas as idades e capacidades. A coordenação e capacidade aos níveis global, regional e nacional serão reforçadas para responder às necessidades de apoio técnico, inovação e orientação (OMS, 2018).

A OMS é o órgão responsável por esse trabalho e, por isso, irá incidir nas seguintes áreas-chave: facilitar e promover parcerias multisetoriais; desenvolver e disseminar políticas, diretrizes e ferramentas; catalisar a inovação e soluções digitais; 
promover a ação política; o estabelecimento de parcerias e a participação de múltiplos grupos e comunidades; apoiar a transferência do conhecimento; promover o investimento na investigação e avaliação; apoiar a mobilização de recursos; oferecer suporte técnico; estabelecer parcerias para a capacitação dos profissionais e monitorizar o progresso e o impacto (OMS, 2018)

Entre as 9 citações a respeito do Lazer que a Agenda "Global action plan on physical activity 2018-2030: More active people healthier world" apresenta, surgem 3 aspectos importantes, ou seja, a manifestação cultural com 4 citações, espaço-lugar com 3 aparições e o aspecto tempo com 2 menções.

Referente a manifestação cultural, ações são propostas para as partes interessadas, os chamados "stakeholders", com o intuito de que sejam oferecidas oportunidades e programas apropriados de atividade física para diferentes populações de pacientes. A seguir, pode-se ver tal exemplo na citação abaixo:

As partes interessadas no setor governamental e privado de recreação, esporte e lazer devem aconselhar potenciais e, quando apropriado, desenvolver parcerias com prestadores de serviços de saúde para apoiar o fornecimento de oportunidades e programas apropriados de atividade física para diferentes populações de pacientes (OMS, 2018, p. 80).

O segundo aspecto ressalta o Lazer como espaço-lugar e trata das políticas que melhoram e/ou incentivam a implementação das instalações esportivas e de lazer. Este espaço de lazer nos bairros locais tem o própósito, na Agenda, em melhorar a saúde, o bem-estar da comunidade e a qualidade de vida. Como podemos observar na citação a seguir, o lazer citadino faz parte da agenda da saúde ao privilegiar a atividade física seja praticada em áreas naturais urbanas, a exemplo de parques (áreas verdes) e lagos (áreas azuis): 
Políticas que melhoram a segurança rodoviária, promovem o design urbano compacto e priorizam o acesso de pedestres, ciclistas e usuários do transporte público a destinos e serviços, principalmente educacionais, espaços públicos abertos e verdes e "azuis", instalações esportivas e de lazer, podem reduzir o uso de transporte pessoal motorizado, emissões de carbono, congestionamento de tráfego e custos com assistência médica, além de impulsionar as microeconomias nos bairros locais e melhorar a saúde, o bemestar e a qualidade de vida da comunidade. Devido ao mundo cada vez mais urbanizado, com mais de $70 \%$ da população global vivendo em centros urbanos, as cidades têm responsabilidade e oportunidade especiais de contribuir com essa agenda, melhorando o design urbano e os sistemas de transporte sustentáveis (OMS, 2018, p. 17).

O terceiro aspecto ressalta o tempo de lazer como elemento do tempo livre. Tal aspecto pode ser exemplicado na citação abaixo:

Os Estados Membros são incentivados a fortalecer a comunicação de dados
desagregados de acordo com as recomendações acordadas e a refletir as
prioridades duplas deste plano de ação, a saber: (i) diminuir o nível geral de
inatividade física na população e (ii) reduzir as disparidades nos países e os
níveis de inatividade física nas populações menos ativas, identificadas em
cada país. Os dados desagregados devem incluir medidas específicas de
domínio da atividade física (relacionadas ao trabalho, caminhada, ciclismo e
lazer), bem como a apresentação por fatores sociodemográficos, culturais,
econômicos e geográficos (OMS, 2018, p. 46).

Neste caso, o propósito dessa agenda é aumentar o nível da atividade física da população em geral no período do tempo livre com o objetivo de melhorar a saúde, a partir de um plano de ação para diminuir o nível de inatividade física na população, e reduzir as disparidades e níveis de inatividade física nas populações menos ativas, identificadas pelos diferentes países.

\section{3) Megatendências Mundiais 2030 - IPEA, 2015}

Considerando que o Brasil está cada vez mais inserido na globalização, o conhecimento de cenários globais é o primeiro passo para a construção de estratégias e de políticas públicas sinérgicas e eficazes. O conhecimento das visões a respeito do futuro, desenvolvido por diversas entidades e personalidades ao redor do mundo, também é a chave nesse processo, pois contribui para a redução de pontos cegos e para 
a análise de impactos na sociedade brasileira. As visões servem, igualmente, para traçar cenários prováveis e desejados, facilitando a escolha de opções estratégicas de adaptação e até mesmo de modificação de tendências atuais, considerando os interesses e as aspirações da sociedade brasileira (IPEA,2015).

Conforme Ipea (2015), este documento busca planejar o futuro do mundo e suas tendências é um convite à reflexão sobre os desafios e as oportunidades para o Brasil ocupar um lugar melhor no mundo. A fim de tomar decisões acertadas que permitam concretizar as aspirações de sua sociedade, o Brasil não pode deixar de conhecer e de acompanhar as tendências e as trajetórias dos diversos campos do conhecimento. Com isso, este documento busca estimular o aprofundamento de uma cultura e de uma prática de pensamento estratégico e de planejamento de longo prazo em diversas instâncias do país.

O Instituto de Pesquisa Econômica Aplicada possui como atribuição fornecer suporte técnico e institucional às ações governamentais para a formulação e a reformulação de políticas públicas e de programas brasileiros de desenvolvimento, considerando a situação presente e as possibilidades de futuro, assim como a preparação de políticas públicas e de ações de governo (IPEA, 2015).

Nessa perspectiva, o Ipea (2015) apresenta este documento que investiga e divulga as possibilidades de futuro, no qual as ideias resumidas traduzem o pensamento de várias entidades e personalidades internacionais.

Essa obra tem por objetivo apresentar à sociedade brasileira, em particular aos planejadores e aos executores de políticas públicas, um conjunto de megatendências e o que essa entidade denomina de as "sementes de futuro" nas áreas de população e sociedade, de geopolítica, de ciência e tecnologia, de economia e de meio ambiente (IPEA, 2015).

licere, Belo Horizonte, v.23, n.2, jun/2020. 
Desde 1930, por meio dos mais diversos processos de planejamento estratégico, já se buscava extrair visões convergentes para o futuro do Brasil. A visão de futuro do país é historicamente otimista, sempre apontando para um futuro brilhante. No entanto, percebe-se que, em muitos desses exercícios, o macroambiente mundial em que ele estava inserido era analisado de maneira superficial, quando não desconsiderado (IPEA, 2105).

Os países considerados as grandes potências mundiais monitoram incessantemente os movimentos e as estratégias dos principais atores públicos e privados. Eles não se contentam em torcer para que as escolhas dos outros atores sejam convergentes com as suas necessidades e aspirações. O IPEA convoca o leitor a construir, no presente, o país do futuro, por isso necessitamos estar permanentemente atentos ao contexto ambiental no qual estamos inseridos. Todavia, avalia prejudicial a leitura equivocada da realidade, seja o otimismo exacerbado sobre o futuro ou aceitar passivamente que o nosso destino seja traçado por outros (IPEA, 2015).

Entre as 12 citações a respeito do Lazer contidas na Agenda Megatendências 2030, podem ser destacados dois aspectos significativos nas 11 citações referentes a manifestação cultural e 1 uma citação que ressalta o lazer com ênfase no espaço-lugar.

No primeiro aspecto, o lazer surge como manifestação cultural sendo valorizado o investimento e o desenvolvimento na ciência e tecnologia, bem como nas TIC's, exemplificada na citação abaixo:

\footnotetext{
Nos estudos analisados, foram identificadas quatro megatendências, listadas a seguir, e 21 sementes de futuro relacionadas a essas megatendências, conforme será abordado ao longo deste capítulo. As megatendências são: • aceleração do desenvolvimento tecnológico, multidisciplinar, com aplicações tecnológicas cada vez mais integradas; • as TIC continuarão modificando a natureza do trabalho, a estrutura de produção, de educação, de relação entre as pessoas e lazer; • crescimento dos investimentos em automação e robótica; - crescimento dos investimentos e aplicação no campo da nanotecnologia e biotecnologia (IPEA, 2015).
} 
O espaço-lugar, é o segundo tipo de discussão, aparece no capítulo 3 e trata da ciência e tecnologia, bem como, do crescimento dos investimentos em automação e robótica, e será exemplificado na citação abaixo:

\begin{abstract}
Sendo assim, o crescimento dos investimentos em automação e robótica pelas organizações vão gerar alterações significativas nos processos produtivos e de gestão. A expectativa é que, no futuro não muito distante, tanto a automação quanto a robótica estarão muito mais presentes em nossas vidas, sejam em nossas casas, nos espaços de lazer e ou ambiente de trabalho (IPEA, 2015, p. 110).
\end{abstract}

Portanto, na perspectiva econômica do IPEA, o lazer é valorizado especialmente porque será o objeto (tempo, manifestação e lugar) que receberá, quase que passivamente, as influências tecnológicas. A relação entre lazer e consumo é exacerbada neste prognóstico, com pouca reflexividade para a dimensão atitude do lazer. A nosso ver, a "agência" das pessoas, mesmo que limitada, nesse caso, precisa ser considerada como contraponto pedagógico (educação para o lazer) frente ao determinismo econômico.

\title{
4) Brasil 2035: Cenários para o Desenvolvimento - IPEA, 2017
}

Esta Agenda é resultado de um trabalho desenvolvido no "Projeto Brasil 2035:construindo hoje o país de amanhã", liderado pelo Núcleo de Cenários e Estudos Prospectivos do Instituto de Pesquisa Econômica Aplicada (Nucen/Ipea) e pela Associação Nacional dos Servidores da Carreira de Planejamento e Orçamento (Assecor), com a participação da Embrapa e outras instituições de pesquisa e desenvolvimento do país (IPEA, 2017).

Vale lembrar que já analisamos a visão do IPEA sobre o cenário exterior no documento IPEA, 2015 e que a presente agenda, por sua vez, é um prognóstico nacional para fornecer uma visão como será o país em 2035. 
Para o Ipea (2017), o documento tem o objetivo de identificar elementos que subsidiem a formulação de estratégias de desenvolvimento para o Brasil, tendo, como horizonte temporal, o ano de 2035, com a participação de mais de 800 especialistas da academia, sociedade civil, Forças Armadas, sistema financeiro, economia real e administração pública.

A coordenadora do projeto Elaine Coutinho Marcial, e os especialistas se empenharam na análise de quatro dimensões setoriais (econômica; social; políticoinstitucional; territorial) três transversais (água; meio ambiente e ciência e tecnologia), além de temáticas de interesse dos parceiros (bioeconomia, financiamento de longo prazo, energia, previdência; paz, defesa e segurança internacional, entre outras (IPEA. 2017).

Segundo Ipea (2017) foram realizadas discussões dos cenários sobre os aspectos sociais, econômicos, político-institucionais, territoriais um estudo específico sobre desafios e oportunidades em questões fundamentais para apoiar o desenvolvimento sustentável da agricultura brasileira e de outras áreas.

A construção de uma estratégia de desenvolvimento para o país que oriente as ações dos agentes públicos e privados exige planejamento. A viabilização da implementação dessa estratégia demanda que o planejamento, e os planos dele oriundos, esteja associado a ferramentas de gestão e aos recursos orçamentários disponíveis de acordo com as capacidades reais do Estado. Por isso, o nosso arcabouço constitucional amarrou essas peças, alinhando o Orçamento Anual com o Plano Plurianual (PPA), por meio da Lei de Diretrizes Orçamentárias (LDO). O curto prazo ficaria, assim, submetido às definições estratégicas de médio prazo para o país, que deveriam se orientar pelos grandes objetivos da nação, já definidos na nossa Carta Magna (IPEA, 2017).

licere, Belo Horizonte, v.23, n.2, jun/2020. 
Como diagnóstico percebe-se que não existem bons sistemas de antecipação e de modelagem de futuros possíveis, corre-se o sério risco de se realizarem escolhas equivocadas ou apenas de se tentar seguir rumo ao futuro mirando o retrovisor. A incapacidade de vislumbrar futuros possíveis e fazer escolhas inteligentes traz riscos substanciais para os ambientes de negócios e para a competitividade e a sustentabilidade das organizações (IPEA, 2017).

Conforme o documento Brasil 2035, o discurso de justificação do prognóstico é que se deve responder às realidades de um mundo cada vez mais fluido e mutável, é preciso ampliar a capacidade de antecipar futuros possíveis, de realizar escolhas inteligentes e planejar de forma cada vez mais sofisticada e competente. A incorporação de práticas de inteligência estratégica se torna, mais que uma necessidade, um imperativo na vida das organizações, que precisarão mirar alvos cada vez mais difusos e móveis (IPEA, 2017).

É por isso que o Brasil precisa investir em plataformas e centros de inteligência capazes de coletar, analisar e disseminar, de forma sistemática, informações sobre tendências gerais dos mercados e possíveis trajetórias do processo de inovação e suas implicações para a competitividade dos negócios. Tal capacidade é essencial para subsidiar as tomadas de decisão e para definir políticas públicas adequadas ao atingimento de metas estratégicas de desenvolvimento do país (IPEA, 2017).

O Instituto de Pesquisa e Economia Aplicada (IPEA) é uma fundação pública vinculada ao Ministério do Planejamento, Desenvolvimento e Gestão, que fornece suporte técnico e institucional às ações governamentais, possibilitando a formulação de inúmeras políticas públicas e programas de desenvolvimento brasileiros, e que disponibiliza, para a sociedade, pesquisas e estudos realizados por seus técnicos (IPEA, 2017).

licere, Belo Horizonte, v.23, n.2, jun/2020. 
Entre as 6 citações apresentadas a seguir a respeito do Lazer na Agenda "Brasil 2035: cenários para o desenvolvimento" verificou-se 2 aspectos significativos, ou seja, a manifestação cultural com 5 citações e o tempo com 1 aparição. A manifestação cultural é encontrada, como exemplo, no capítulo 19, demonstrando que as TIC's continuarão influenciando mudanças no comportamento humano. A seguir, pode-se ver tal questão na citação abaixo:

\begin{abstract}
A sociedade brasileira está entre as que mais utilizam redes sociais como Facebook, Instagram, Twitter, Youtube e Whatsapp do mundo. Além das redes sociais, compras on-line, aplicativos de localização, relacionamento, lazer, trabalho, transporte, entretenimento e finanças são apenas alguns exemplos de como as TICs estão presentes no cotidiano dos brasileiros (IPEA, 2017, p. 257).
\end{abstract}

O segundo aspecto ressalta o tempo de lazer no capítulo 8, demonstrando o panorama internacional em um mundo em transformação até 2035 , como podemos inferir no fragmento abaixo:

\begin{abstract}
O ambiente será propício para o desenvolvimento da internet das coisas, onde produtos e serviços serão desenvolvidos, integrados a diversas mídias e conectados via internet, remodelando o ambiente de produção e o dia a dia das pessoas. As principais áreas que devem apresentar desenvolvimento integrado são a da biotecnologia, da nanotecnologia, das TICs e das tecnologias dos materiais. As TICs continuarão modificando a natureza do trabalho, a estrutura de produção, a educação, a forma como as pessoas se relacionam e a utilização de seus períodos de lazer (IPEA 2017, p. 111).
\end{abstract}

Neste aspecto, além de mostrar que as principais áreas que apresentam o desenvolvimento integrado são a da biotecnologia, da nanotecnologia, das TICs e das tecnologias dos materiais mostra também, que será mantido o crescimento da conectividade, a convergência tecnológica, a interatividade, com acesso ubíquo em alta velocidade.

\title{
5) Visão 2035: Brasil, País Desenvolvido - BNDES, 2018
}

O documento "Visão 2035: Brasil, país desenvolvido - agendas setoriais", traz projeções de futuro para 17 setores da economia. Foram explorados três cenários 
possíveis, para cada setor, baseados nas seguintes perguntas: a) "o que seria necessário para destravar o setor?”; b) “o que deveria acontecer para potencializar o setor?”; e c) “como seria possível transformar o setor?” (BNDES, 2018).

Ele reúne duas antigas tradições do BNDES. A primeira delas é a produção de análises setoriais, que remonta à criação do Banco, em 1952. A segunda refere-se ao uso de técnicas de cenários para planejamento estratégico, utilizadas na instituição desde 1980. Nesta agenda, análises setoriais e técnicas de cenários se combinam imbuídas de um terceiro elemento: o espírito de ousadia do processo de reflexão e planejamento estratégico, em curso no Banco (BNDES, 2018).

O documento discursa sobre uma ampla agenda setorial possível de ser implementada, que tem muito a contribuir para promover o desenvolvimento do país. Parte significativa dessa, consiste em medidas de fácil adoção, mas de grande efeito e de retornos em curto e médio prazos. Em um cenário mais ambicioso, pressupondo que os desafios relacionados a agenda serão superados, e que surgirão iniciativas mais ambiciosas e de longo prazo, tem-se a perspectiva de uma verdadeira transformação da economia (BNDES, 2018).

Como diagnóstico, os cenários dessa agenda buscam evitar dois erros comuns: a mera projeção de tendências do passado e o equívoco de transformar instabilidades conjunturais em tendências de longo prazo, subestimando fatores de continuidade e questões estruturais. Ao contrário do que geralmente se supõe, é justamente a existência da incerteza em seu sentido forte o que justifica a criação de cenários. Eles servem para basear uma atitude ativa e criativa em relação à construção de tempos mais promissores e evitar riscos que comprometam o desenvolvimento do país, a longo prazo (BNDES, 2018). 
Como prognóstico, é colocar em debate uma agenda de propostas setoriais, com medidas para "destravar", "potencializar" ou "transformar" a economia brasileira, tendo por propósito último “tornar o Brasil um país desenvolvido até 2035”. Algumas medidas têm custo fiscal, mas a maioria não tem. Há propostas de reestruturação tributária que podem até melhorar a arrecadação, além dos ganhos de receitas advindos do maior crescimento (BNDES, 2018).

O Banco Nacional de Desenvolvimento Econômico e Social (BNDES) foi fundado em 1952 e é um dos maiores bancos de desenvolvimento do mundo e, hoje, o principal instrumento do Governo Federal para o financiamento de longo prazo e investimento em todos os segmentos da economia do país. $\mathrm{O}$ banco apoia empreendedores de todos os portes, pessoa física, na realização de seus planos de modernização, de expansão e na concretização de novos negócios, tendo sempre em vista o potencial de geração de empregos, renda e de inclusão social para o Brasil (BNDES, 2018).

Entre as 5 citações a respeito do Lazer que a Agenda "VISÃO 2035: Brasil, país desenvolvido" nos traz, observamos que a faceta manifestação cultural é a mais destacada, com 5 citações. Tal aspecto é visto no capítulo da Indústria Automotiva, que descreve sobre o futuro desta indústria e as perspectivas para o Brasil, exemplificado com a citação abaixo:

\footnotetext{
Embora algumas formas de automação já estejam disponíveis há anos - como é o caso do assistente de estacionamento, do controle de velocidade e do auxílio para manutenção na faixa -, por enquanto, a automação em nível comercial ainda é limitada. No médio prazo, os carros autônomos talvez não sejam equipados com todos os dispositivos disponíveis em residências ou escritórios, mas pelo menos deverão se conectar com outros carros (V2V), com sistemas de transporte e com a infraestrutura (V2I) rodoviária, obtendo melhores direções de trânsito. Outros recursos são a mídia interativa, as conexões com opções de lazer e comércio varejista, o acesso a notícias e entretenimento etc (BNDES, 2018, p. 202).
}

Reiteradamente, esse documento também destaca que, em última instância, o lazer e suas variantes são afetados pelas inovações tecnológicas com origem na questão

licere, Belo Horizonte, v.23, n.2, jun/2020. 
econômica. Isto chama atenção que o desenvolvimento da automação se fez muito mais presente no lazer do que no trabalho.

Na nossa interpretação, citação é que o valor da força de trabalho, em algumas situações, ainda está tão barato e vai continuar que a automação está menos presente no trabalho do que no lazer, pois no lazer gera consumo e renda enquanto no trabalho, a mão de obra está barata e não compensa economicamente a automação. Isto acontece nas compras online, enquanto a Inteligência Artificial (IA) constrói o "big data".

\section{6) Curitiba 2035 - Senai/PR, 2017}

Segundo o documento Curitiba 2035, como diagnóstico da situação atual, o processo de urbanização é uma tendência marcante em países em estágio de desenvolvimento como o Brasil. Esse fenômeno traz em seu bojo a exacerbação de problemáticas relativas à vida em territórios com grandes aglomerações humanas. Grandes centros urbanos, como Curitiba, buscam energia, saneamento básico, educação, saúde, segurança, moradia, acolhimento social, mobilidade, geração de empregos, entre outros, compondo assim uma complexa e desafiadora lacuna a ser preenchida constantemente (SENAI/PR, 2017).

A natureza desses desafios exige soluções sustentáveis em intervenções estruturantes e que, sobretudo, tenham perenidade, pois a característica principal de projetos e iniciativas de caráter estruturante e que estes demandam mais tempo para implementação e os resultados mais significativos são colhidos em médio e longo prazos (SENAI/PR, 2017).

Para a realização da agenda local "Curitiba 2035", a iniciativa foi feita com participação da sociedade por meio de dinâmicas de criação de inteligência coletiva e fruto de uma parceria entre Comunitas, Instituto Arapyaú, Sistema Federação das 
Indústrias do Estado do Paraná (Sistema FIEP) e Prefeitura Municipal de Curitiba (PMC) (SENAI/PR, 2017).

Curitiba 2035 tem como objetivo o propósito de explicitar o futuro almejado pela sociedade e, com isso, orientar o processo de desenvolvimento sustentável da cidade (SENAI/PR, 2017).

Como prognóstico, o documento busca sistematizar o trabalho efetuado com vistas a instrumentalizar as aspirações e o sonho da sociedade curitibana, bem como de suas interrelações metropolitanas, no sentido de auferir um crescimento ordenado, com desenvolvimento socioeconômico que prima pelo bem-estar e qualidade de vida da comunidade (SENAI/PR, 2017).

Este documento traduz o mapa do caminho a ser percorrido para a concretização do futuro desejado para a cidade. O sucesso dessa construção cidadã está indubitavelmente vinculado a capacidade de articulação e ao comprometimento social, implicando gestores públicos e privados, tomadores de decisão, formadores de opinião e “stakeholders” diversos na sua consecução (SENAI/PR, 2017).

Entre as 18 citações a respeito do Lazer que a agenda "Curitiba 2035" nos traz, surgem 2 importantes elementos que são o espaço-lugar com 10 citações e a manifestação cultural com 8 aparições.

O primeiro elemento espaço-lugar é demonstrado nos temas Saúde e Qualidade de Vida que foram compreendidas como questões significativas para o processo de planejamento de longo prazo para a Cidade de Curitiba, pois são temas que colocam em relevo uma questão fundamental a ser alcançada no espaço urbano, ou seja, a melhoria nas condições de bem-estar dos indivíduos em sociedade, e isto pode ser exemplificado na citação abaixo: 
associada a aspectos como cultura, esporte, lazer e demais condicionantes que favorecem a melhoria de vida das pessoas nas perspectivas física, mental, social e espiritual (SENAI/PR 2017, p.82).

O segundo aspecto ressalta a manifestação cultural que está evidenciada a partir da implementação de ações estratégicas em Saúde e Qualidade de Vida buscando assim legitimidade no documento Curitiba 2035, que está diretamente imbricada aos processos de desenvolvimento humano e da cidade e isto será exemplificado na citação abaixo:

\begin{abstract}
No que tange a Qualidade de Vida, o tema ganha crescente importância em virtude do interesse dos cidadãos por uma vida agradável, com estruturas sociais que permitam bem-estar e satisfação. Nesse sentido, o conceito de escala humana se consolida, ou seja, a cidade passa a ser planejada de forma orientada as pessoas. Além disso, essa mesma cidade disponibiliza acesso à cultura, nas suas múltiplas expressões, assim como oferta esporte e lazer para recreação, entretenimento e aptidões física e mental (SENAI/PR 2017, p. 82).
\end{abstract}

\title{
O Lazer e os Temas Articuladores das Agendas
}

Como essas agendas são de setores não-específicos do campo do lazer, foi comum a apropriação de apenas um elemento constituinte desse fenômeno. Nesse sentido, apresentamos também a discussão setorial por temas: saúde, qualidade de vida, direito social, desenvolvimento econômico, desenvolvimento sustentável, bem como, outros temas que serão pertinentes que serão conhecidos abaixo.

Desta forma, trazemos o entendimento do tema, a partir dos organismos signatários da agenda e, em seguida, identificamos como o lazer está articulado ao tema da agenda.

\section{1) Saúde}

Entendida como estado de completo bem-estar físico, mental e social, e não apenas a ausência de doenças. Esta definição é a mais difundida e foi encontrada nos registros oficiais da Organização Mundial da Saúde (OMS). Para a Agenda Global da OMS (2018), a saúde está diretamente relacionada a conscientização da prática regular 
de atividade física em ambientes sustentáveis como em parques, matas, praias visando a preservação destes espaços.

Como o lazer é referenciado: $\mathrm{O}$ aumento da participação da atividade física em ambientes naturais estimula o uso sustentável, a valorização, conservação e restauração da terra e da biodiversidade. $\mathrm{O}$ aumento da valorização desses espaços aumenta a demanda pela preservação dos ambientes naturais, possibilitando a atividade física sustentável, a recreação ativa e o lazer. A preservação destes habitats naturais também pode deter a perda de biodiversidade e ajudar a proteger/prevenir a extinção de espécies ameaçadas (OMS, 2018).

\section{2) Qualidade de Vida (QV):}

Para a OMS, a definição de QV é a "a percepção que um indivíduo tem sobre a sua posição na vida, dentro do contexto dos sistemas de cultura e valores nos quais está inserido e em relação aos seus objetivos, expectativas, padrões e preocupações”. Tratase de uma definição que contempla a influência da saúde física e psicológica, nível de independência, relações sociais, crenças pessoais e das suas relações com características inerentes ao receptivo meio na avaliação subjetiva da qualidade de vida individual. Neste sentido, poderemos afirmar que a qualidade de vida é definida como a "satisfação do indivíduo no que diz respeito à sua vida cotidiana”.

Neste contexto, o lazer aparece como uma manifestação do Estado do bem-estar social e tem como propósito reconhecer o lazer como a qualidade de vida e direito social adquirido das pessoas que vivem em países industrializados que investem em habitação, lazer e seguridade e bem-estar social.

Como o lazer é referenciado: Nos países industrializados da Organização de Cooperação e Desenvolvimento Econômicos, no mesmo ano, a porcentagem de gastos do Governo central com habitação, lazer e seguridade e bem-estar social ia de um 
mínimo de 29,3 por cento a um máximo de 49,4 por cento, com uma média de 39 por cento (Banco Mundial, Relatório sobre o Desenvolvimento Mundial, 1991) (MMA, 2019, p. 61).

\section{3) Desenvolvimento Econômico}

O desenvolvimento econômico trata principalmente de aspectos qualitativos relacionados ao crescimento da economia, não se restringindo ao crescimento da produção. Tal desenvolvimento é capaz de gerar riquezas e melhoria na qualidade de vida da população de uma região, enquanto contribui para o equilíbrio social, o respeito ao meio ambiente e à cultura regional (BNDES,2018).

Como o lazer é referenciado: "As montanhas são uma fonte importante de água, energia e diversidade biológica. Além disso, fornecem recursos fundamentais -como minérios, produtos florestais e produtos agrícolas - e são fonte de lazer. Enquanto importante ecossistema que representa a ecologia complexa e inter-relacionada de nosso planeta, os ambientes montanhosos são essenciais para a sobrevivência do ecossistema mundial (Agenda 21, p. 139).

\section{4) Direito Social}

No artigo $6^{\circ}$ da Constituição Federal de 1988, é definido como direito social, ao lado da educação, da saúde, da alimentação, da moradia, da segurança, da previdência social, entre outros. Ele busca melhorar as condições de vida e de trabalho cedidos à todos pelo Estado, com o auxílio de outras leis, alcançam diferentes áreas de amparo a sociedade como: direitos trabalhistas, direito ao lazer, seguridade social (direitos à 
saúde, à previdência social e à assistência social), proteção à maternidade, à infância e aos desamparados (GOMES e ISAYAMA, 2015).

No nosso estudo, toda vez que aparece o lazer com o propósito de direito social está relacionado, normalmente com a Agenda 21. Ele tem a manifestação do Estado do bem-estar social e tem como o objetivo de melhorar a economia dos países de baixa renda, reconhecer o lazer como a qualidade de vida e a busca do lazer como direito social das pessoas destes países.

Como o lazer é referenciado: Não há cifras globais para os gastos internos nem para o apoio oficial ao desenvolvimento no que diz respeito a assentamentos humanos. No entanto, os dados disponíveis no Relatório sobre o Desenvolvimento Mundial, 1991, para 16 países em desenvolvimento de baixa renda, mostram que a porcentagem de gastos do Governo central com habitação, lazer e seguridade e bem-estar social para 1989 era, em média, de 5,6 por cento, com uma alta de 15,1 por cento no caso do Sri Lanka, que implantou um enérgico programa para a habitação (MMA, 2019, p.61).

\section{5) Tecnologia}

Tecnologia é um termo que envolve o conhecimento técnico e científico e a aplicação deste conhecimento através de sua transformação no uso de ferramentas, processos e materiais criados e utilizados a partir de tal conhecimento. Na economia, a tecnologia é o estado atual de nosso conhecimento de como combinar recursos para produzir produtos desejados (e nosso conhecimento do que pode ser produzido). Existe um equilíbrio grande entre as vantagens e as desvantagens que o avanço da tecnologia traz para a sociedade. A principal vantagem é refletida na produção industrial: a tecnologia torna a produção mais rápida e maior e, sendo assim, o resultado final é um produto mais barato e com maior qualidade (CATTANI e HOLZMANN, 2011). 
No nosso estudo a tecnologia mencionada na maioria das vezes está relacionada com as Tecnologias de Informação e Comunicação (TICs). As TICs podem ser entendidas como um conjunto de recursos tecnológicos que proporcionam um novo e mais rápido modo de se comunicar.

Como o lazer é referenciado: As principais áreas que devem apresentar desenvolvimento integrado são a da biotecnologia, da nanotecnologia, das TICs e das tecnologias dos materiais. As TICs continuarão modificando a natureza do trabalho, a estrutura de produção, a educação, a forma como as pessoas se relacionam e a utilização de seus períodos de lazer (IPEA, 2017).

\section{6) Educação}

Está relacionada ao duplo aspecto educativo do lazer que envolve a educação para e pelo lazer. Aproveitar os momentos de lazer para contribuir com o processo de formação/educação já em andamento. A possibilidade de ampliação do espaço educacional sobre os valores do lazer na escola e para além dos muros escolares, especialmente com a utilização da rede Internet, tendo em vista a perspectiva de desenvolvimento nos níveis pessoal e social, enfatizando-se, inclusive, o espírito de cidadania e de aquisição de direitos (SCHWARTZ et al. 2000).

Como o lazer é referenciado: o destaque é no tópico relativo à Promoção do ensino, da conscientização e do treinamento. Os países devem promover, quando apropriado, atividades de lazer e turismo ambientalmente saudáveis, baseando-se na Declaração de Haia sobre Turismo (1989) e os programas atuais da Organização Mundial de Turismo e o PNUMA, fazendo uso adequado de museus, lugares históricos, jardins zoológicos, jardins botânicos, parques nacionais e outras áreas protegidas (MMA, 2019, p.360). 


\section{7) Desenvolvimento Sustentável}

É a capacidade de suprir as necessidades da geração atual, sem comprometer a capacidade de atender as necessidades das futuras gerações. É aquele desenvolvimento que não esgota os recursos para o futuro. Criada pelas Nações Unidas, essa definição surgiu na Comissão Mundial sobre Meio Ambiente e Desenvolvimento, com a finalidade de discutir e propor meios de harmonizar, simultaneamente, o desenvolvimento econômico e a conservação ambiental (MMA, 2019, 1992).

Como o lazer é referenciado: $O$ aumento da participação da atividade física em ambientes naturais estimula o uso sustentável, a valorização, conservação e restauração da terra e da biodiversidade. O aumento da valorização desses espaços aumenta a demanda pela preservação dos ambientes naturais, possibilitando a atividade física sustentável, a recreação ativa e o lazer. A preservação destes habitats naturais também pode deter a perda de biodiversidade e ajudar a proteger/prevenir a extinção de espécies ameaçadas (OMS 2018, p.59).

\section{8) Infraestrutura Urbana}

Para a Agenda Curitiba 2035, refere-se ao conjunto de serviços básicos indispensáveis a uma cidade ou sociedade, como abastecimento e distribuição de água, gás, energia elétrica, rede telefônica, serviços básicos de saneamento, transporte público e outros (SENAI/PR, 2017).

No nosso estudo, a palavra infraestrutura foi citada 91 vezes no Curitiba 2035, pois abrange todas as Temáticas Prioritárias para o Futuro de Curitiba, que são elas: a) Cidade da educação e do conhecimento, b) Desenvolvimento socioeconômico, c) Mobilidade e transporte, Saúde e qualidade de vida, d) Meio ambiente e biodiversidade, 
e) Coexistência em uma cidade global, f) Planejamento e gestão urbana, g) Segurança e

h) Governança.

Como o lazer é referenciado: Este fator crítico abrange o conjunto de decisões, planos, procedimentos e metas governamentais voltados para a resolução de problemas de interesse público relacionados a área temática Cidade da Educação e do Conhecimento. Ampliação de programas orientados ao uso comunitário de infraestruturas educacionais para atividades de lazer e cultura (SENAI/PR 2017, p. 37).

\section{9) Gestão Urbana}

A gestão urbana é um processo de planejamento, intervenção, regulação e mediação que se aplica para o desenvolvimento dos espaços públicos das cidades. O uso racional do espaço urbano deve ser gerido no sentido de conferir possibilidades de uma existência segura, confortável, saudável e democrática (SILVA e PORTO, 2003).

No nosso estudo, a gestão urbana surgiu como um dos propósitos da Agenda Curitiba 2035. Este programa visa o planejamento e a gestão urbana do futuro de Curitiba com êxito, este eixo busca elaborar planos ou programas para coordenar ações preventivas ou necessárias no contexto urbano local, sistematizando práticas administrativas e um futuro próspero para a cidade. Segundo o documento Curitiba 2035, a cidade se configura como a oitava maior capital brasileira e tem mais de 1,9 milhões de habitantes, alcançando a terceira possível na colocação geral do Índice de Bem-estar Urbano (IBEU) do Brasil (SENAI/PR, 2017).

Como o lazer é referenciado: Este fator crítico abrange processos de planejamento, execução, monitoramento e avaliação de políticas, programas e demais atividades que integram a gestão da cidade e da região metropolitana, buscando uso eficiente dos recursos disponíveis (financeiros, humanos, tecnológicos, físicos, etc.) e 
otimização dos resultados, tendo em vista o alcance da visão de futuro desenhada para o tema Coexistência em uma Cidade Global. Ampliação da agenda e da divulgação de eventos de cultura, esporte e lazer de acesso gratuito nos espaços públicos. Coexistência em uma Cidade Global -Gestão - Ações de Curto prazo (2017-2020) (SENAI/PR 2017, p. 126).

A exegese crítica do material apontou que o lazer é analisado de forma parcial, predominantemente como um campo afetado pelo desenvolvimento tecnológico e econômico ou como meio para promoção da saúde no contexto do desenvolvimento social e ambiental. Também estão parcializadas a dimensões do lazer: tempo, espaçolugar, manifestações culturais e ações/atitude (GOMES, 2004), de forma que o protagonismo das pessoas quanto ao lazer pende entre consumir ou ofertar manifestações e espaços no tempo de não-trabalho.

Uma das possibilidades teóricas para respaldar as agendas é entender o lazer como conteúdo, seja ele a cultura usufruída no tempo disponível (MARCELLINO, 1999) ou as atividades praticadas no tempo liberto das necessidades (DUMAZEDIER, 1994). Essa visão, em nossa leitura, é tão parcial quanto a que identificamos na abordagem fragmentada que os documentos fazem do lazer, especialmente negligenciando a dimensão da agência que, a nosso ver, é a atitude, lócus de fluidez tanto da passividade ou da resistência.

Frente a isso, em inspiração foucaultiana, podemos interpretar alternativamente o lazer contemporâneo como um dispositivo. Nesse caso, sua existência responde inicialmente ao triplo acontecimento das revoluções protestante, industrial e francesa (democracia burguesa). Tal fenômeno tem sua episteme gestada a partir da centralidade européia, quando o acúmulo colonialista permitiu um salto no desenvolvimento do capitalismo e a possibilidade de haver o tempo livre como excedente racionalizado pago 
pelo tempo de trabalho. Frente essa possibilidade material e histórica, o proletariado pôde se organizar para conquista do tempo livre remunerado como direito. Dialeticamente, as relações de poder em torno do lazer vão se complexificando, seja primeiro como dispositivo de controle sobre o tempo livre conquistado pela classe proletária, seja posteriormente, como sedução das massas consumidoras. Mormente o surgimento de instituições estatais ou paraestatais mobilizadas para essa finalidade, as pessoas também estabelecem suas resistências e táticas (PIMENTEL, 2012).

É neste aspecto que, a nosso ver, como a população recebe pouco espaço de agentes no processo. Isto ainda ocorre na Agenda 21 com seus resquícios keynesianos, mas vai diminuindo gradativamente nas agendas mais inspiradas no neo-liberalismo. Daí a necessidade em compreender essas agendas e estabelecer resistências e releituras locais.

\section{Conclusão}

As agendas analisadas perspectivam entre uma e duas décadas. As discussões relacionam lazer com saúde, qualidade de vida, tecnologia, educação, gestão urbana, infraestrutura urbana, desenvolvimento sustentável e direito social.

Como discutido, essas agendas enfatizam o lazer a partir das dimensões manifestação cultural e espaço; a dimensão tempo também é considerada e revela a disputa sobre os usos lícitos do tempo livre. Nesse sentido, a dimensão atitude é pouca considerada na perspectiva da heterodeterminação. Vai se revelar a perspectiva de mudança dos hábitos em prol da geração de renda e de melhoria da saúde em um cenário de desenvolvimento sustentável. E, mesmo com o aumento da influência neoliberal nessas agendas, se vê nelas a tentativa de que o lazer atue no marco 
civilizatório de melhoria da vida nas cidades enquanto mercadoria tecnológica ou estilo de vida saudável compensatória à poluição e ao sedentarismo.

Portanto, o lazer nessas agendas se coloca no plano do inconciliável o que reverberará nos dilemas que as políticas públicas enfrentarão no cenário hodierno de enfraquecimento do cenário keynesiano dos direitos sociais.

\section{REFERÊNCIAS}

BNDES, Visão 2035: Brasil, país desenvolvido: agendas setoriais para alcance da meta. Banco Nacional de Desenvolvimento Econômico e Social; Organizadores: Fernando Puga e Lavínia Barros de Castro. Rio de Janeiro: BNDES, 2018.

BRASIL. Ministério das Relações Exteriores. Conferência das Nações Unidas sobre Meio Ambiente e Desenvolvimento: Agenda 21. Brasília: Diário Oficial da União, 1994.

CATTANI, A. D.; HOLZMANN, L. (Orgs.). Dicionário de trabalho e tecnologia - 2. ed. Porto Alegre, RS: Zouk, 2011.

DUMAZEDIER, J. A revolução cultural do tempo livre. São Paulo: Studio Nobel/SESC, 1994.

GERMANO, J. W.; SILVA, T. C.; COSTA, J. S. G. Saberes ausentes: colonialismo e injustiça cognitiva. Revista Inter-Legere. v. 1, n. 7, p. 168-179, 2013.

GOMES, C. L. verbete Lazer. In: GOMES, C. L (Org.). Dicionário crítico do lazer. Belo Horizonte: Autêntica, 2004.

; ISAYAMA, H. F (Orgs.). O Direito social ao lazer do Brasil: Multiplicidade de olhares sobre o lazer como direito social, São Paulo: Hucitec, 2015.

IPEA. Brasil 2035: cenários para o desenvolvimento / Instituto de Pesquisa Econômica Aplicada, Associação Nacional dos Servidores da Carreira de Planejamento e Orçamento. - Brasília: Ipea: Assecor, 2017.

Megatendências mundiais 2030: o que entidades e personalidades internacionais pensam sobre o futuro do mundo? : contribuição para um debate de longo prazo para o Brasil. MARCIAL, E.C. (Org.). Brasília: Ipea, 2015.

MARCELlinO, N.C. Para tirar os pés do chão. São Paulo: Hucitec, 1999.

MMA. Ministério do Meio Ambiente. Agenda 21. Disponível em: http://www.mma.gov.br/responsabilidade-socioambiental/agenda-21. Acesso em: 07 Ago. 2019.

OMS/WHO. Global action plan on physical activity 2018-2030: more active people for a healthier world. Geneva: World Health Organization, 2018. Licence: CC BY-NCSA 3.0 IGO.

licere, Belo Horizonte, v.23, n.2, jun/2020. 
PIMENTEL, G. G. A. Grupo Estudo de Lazer. In: UVINHA, R. R. Lazer no Brasil: grupos de pesquisa e associações temáticas. São Paulo: Edições Sesc, 2018.

O passivo do lazer ativo. Movimento, v. 18, n. 3, 299-316, 2012.

SCHWARTZ, G.M.; SILVA, R.L. Leisure Education through Web. In: WORLD LEISURE CONGRESS, 6, 2000, Bilbao, Anais... Bilbao, 2000, p. 3-7.

SENAI-PR. Curitiba 2035. Curitiba: Senai/PR, 2017.

SILVA, M. D. G.; MIRANDA, E. de A. Planejamento do turismo para o desenvolvimento local. Revista Brasileira de Planejamento e Desenvolvimento, v. 2, n. 2, p. 94-103, 2013.

SILVA, R.T.; PORTO, M. F. A. Gestão urbana e gestão das águas: caminhos da integração. Estudos avançados, v.17, n. 47, 2003.

SOGREN, M., NATHANIEL, K. A. The Global Agenda: perspectives from the Caribbean. International Social Work, v. 60, n. 2, p. 271-282, 2017.

\section{Endereço dos Autores:}

Ricardo Alves Mendes

Rua Oyapock, $67 \mathrm{apt}^{\mathrm{o}} 501$ - Bairro Cristo Rei

Curitiba - PR - 80.050-450

Endereço Eletrônico: ricardoalvesmendes0303@gmail.com

Giuliano Gomes de Assis Pimentel

Departamento de Educação Física

Avenida Colombo, $\mathrm{n}^{\circ} .5 .790$

Bloco M-06 - Sala 002 - Campus Universitário

Maringá - PR - 87.020-900

Endereço Eletrônico: ggapimentel@uem.br 